\title{
A discrete choice experiment of preferences for genetic counselling among Jewish women seeking cancer genetics services
}

\author{
S Peacock ${ }^{1,2}$, C Apicella ${ }^{3}$, L Andrews ${ }^{4}, K_{\text {Tucker }}^{4}$, A Bankier ${ }^{5}$, MB Daly ${ }^{6}$ and JL Hopper ${ }^{*, 3}$ \\ 'British Columbia Cancer Agency, Cancer Control Research, 675 West IOth Avenue, Vancouver, British Columbia V5Z IL3, Canada; ${ }^{2}$ Department of \\ Health Care and Epidemiology, University of British Columbia, 5804 Fairview Avenue, Vancouver, British Columbia V6T IZ3, Canada; ${ }^{3}$ Centre for \\ Molecular, Environmental, Genetic and Analytic Epidemiology, School of Population Health, The University of Melbourne, Level 2, 723 Swanston Street, \\ Carlton, Victoria 3053, Australia; ${ }^{4}$ Hereditary Cancer Clinic, Prince of Wales Hospital, High St, Randwick, New South Wales 2031, Australia; ${ }^{5}$ Genetic \\ Health Services Victoria, Royal Children's Hospital, Flemington Road, Parkville, Victoria 3052, Australia; ${ }^{6}$ Fox Chase Cancer Center, 333 Cottman Avenue, \\ Philadelphia, PA 191/1-2497, USA
}

To determine which aspects of breast cancer genetic counselling are important to Ashkenazi Jewish women, a discrete choice experiment was conducted. Participants consisted of 339 Australian Ashkenazi Jewish women who provided a blood sample for research used to test for Ashkenazi Jewish ancestral mutations in the genes BRCAI and BRCA2, and were offered their genetic test result through a cancer genetics service. Main outcome measures were women's preferences for, and trade-offs between, the genetic counselling aspects of providing cancer, gene, and risk information (information); giving advice about cancer surveillance (surveillance); preparing for genetic testing (preparation); and, assistance with decision-making (direction). Respondents most valued information, about twice as much as advice about surveillance, four times as much as preparation for testing, and nine times as much as assistance with decision-making, which was least valued. Women's preferences were consistent with the major goals of genetic counselling which include providing information and surveillance advice, and avoiding direction by facilitating autonomous decision-making. There were differences between the women in which aspects they most favoured, suggesting that counselling that elicits and responds to clients' preferences is more likely to meet clients' needs.

British Journal of Cancer (2006) 95, |448- |453. doi:I0.1038/sj.bjc.660345 I www.bjcancer.com

(c) 2006 Cancer Research UK

Keywords: Ashkenazi; breast cancer; BRCAI and BRCA2; discrete choice experiment; client preferences; genetic counselling

Shortly after the cloning of the breast cancer susceptibility genes BRCA1 and BRCA2, three specific mutations in BRCA1 and BRCA2 were found to be 20 times more common in individuals of Ashkenazi Jewish descent than in the general population (Struewing et al, 1997). These ancestral mutations are thought to account for $20 \%$ of all breast cancer in Ashkenazi Jewish women (Satagopan et al, 2001). Carriers of a mutation in either of these genes are at $40-60 \%$ lifetime risk of developing breast cancer and $20-40 \%$ lifetime risk of developing ovarian cancer (Robson et al, 1997; Fodor et al, 1998; Hartge et al, 1999; Satagopan et al, 2001).

In the past decade, there has been a rapid increase in the demand for, and availability of, breast cancer genetics services (Thompson et al, 1995). These services aim to provide women with an estimate of their risk of developing breast and ovarian cancer based on their family history, and in some cases, genetic testing for mutations in BRCA1 and BRCA2 is offered. These services may further aim to improve psycho-social outcomes for clients by inclusion of other specialities and techniques, including, facilitating autonomous decision-making about genetic testing and risk-

*Correspondence: Professor JL Hopper;

E-mail: j.hopper@unimelb.edu.au

Received 5 April 2006; revised 25 September 2006; accepted 28 September 2006 reduction options, preparing clients for the possible outcomes of genetic testing, and offering family or group therapy sessions. In recent years, many services have established multidisciplinary teams including surgeons, oncologists, and gynaecologists so that breast and ovarian cancer surveillance advice can be provided.

Outcomes of genetic counselling may relate to process issues, or may relate to desired client outcomes. Process issues, such as satisfaction with consultation waiting time, location, duration of counselling sessions, and type of service provider, have been examined in a number of studies (Shiloh et al, 1990; Bernhardt et al, 2000; Brain et al, 2000; Metcalfe et al, 2000; Wilson et al, 2000; Holloway et al, 2004; Pieterse et al, 2005a,b). Client outcomes are more difficult to measure than process issues, but are more salient for evaluating and informing service delivery (Clarke et al, 1996; Cappelli et al, 2001). Desired client outcomes, such as reduced anxiety, improved genetic knowledge, and risk perception, have received some attention in the literature (Bernhardt et al, 2000, Metcalfe et al, 2000; Pieterse et al, 2005a, b).

Desired client outcomes may be influenced by several factors including clients' needs, their expectations and their preferences before counselling, and also the fulfilment, or perceived fulfilment, of these factors after counselling. Studies of expectations before genetic counselling have shown that clients often do not know the procedure or structure of the counselling appointment, sometimes resulting in the client feeling that he or she was inadequately 
prepared (Hallowell et al, 1997; Stadler et al, 1998; Berkenstadt et al, 1999; Bernhardt et al, 2000; Holloway et al 2004). Studies of preferences measured before genetic counselling have further shown that clients have high preference for information, although it is difficult to interpret findings regarding preferences for aspects other than information given clients' lack of knowledge about the counselling process before attendance (Cohn et al, 2003; Tiller et al, 2005).

In this study, we elicited preferences for genetic service delivery in Jewish women who had previously participated in a BRCA1 and BRCA2 genetic testing programme, and so had knowledge of the procedures of genetic counselling. The aim of this study was to measure strength of preference for the different aspects of genetic counselling outcomes in these women. Discrete choice experiments are a theoretically valid technique developed by psychologists and economists for eliciting preferences, and are particularly well suited to eliciting preferences for the wide range of health and nonhealth benefits potentially derived from using health services (Ryan, 1999, 2004; Ryan and Farrar, 2000; Sculpher et al, 2004). We used a discrete choice experiment to provide robust information about what aspects clients want most from genetic counselling, the relative value they place on different counselling aspects, and how much value they place on the different aspects.

\section{MATERIALS AND METHODS}

\section{Study sample}

Eligible women were participants in the Australian Jewish Breast Cancer Study (AJBCS) (Apicella et al, 2003) who had previously received their genetic test results and enrolled in the study at least
6 months earlier. Participants recruited in the previous 6 months were excluded because many had not yet attended a genetic clinic for genetic counselling and result disclosure appointments. At recruitment, participants were administered a structured questionnaire developed by the Breast Cancer Family Registry, provided a blood sample that was tested for the Jewish ancestral mutations in BRCA1 and BRCA2, and received genetic information (John et al, 2004). Most women subsequently received their genetic test result through one of six state-funded cancer genetics services, as described previously (Apicella et al, 2006).

\section{Discrete choice experiment}

A follow-up questionnaire was mailed to all 339 participants. The questionnaire included a discrete choice experiment for preferences of attributes (aspects) of genetic counselling. These attributes were identified through reviews of the peer reviewed and policy/practice literature on genetic counselling, consultation with clinical geneticists, genetic counsellors, heads of genetic services, psychologists, and interviews with participants (Apicella et al, 2006). The four identified attributes included in the discrete choice experiment were: providing and explaining cancer, gene and risk information (Information); explaining options and giving advice about appropriate surveillance for breast and ovarian cancer (Surveillance); preparing for the outcomes of genetic testing (Preparation); and, receiving help in deciding whether or not to have a genetic test (Direction).

Descriptions were developed for each of the counselling attributes to help participants understand the nature of each that they were being asked to consider (see Figure 1). The critical task in describing attributes was to ensure they captured the desired client outcomes relevant to women attending the participating

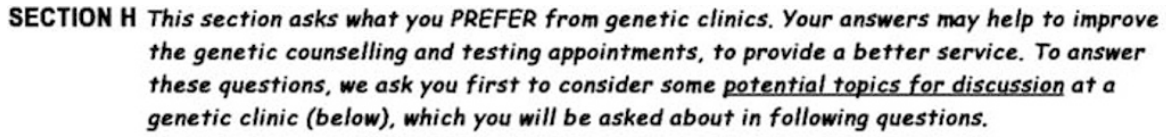

Potential topics for discussion at the genetic counselling appointment include:

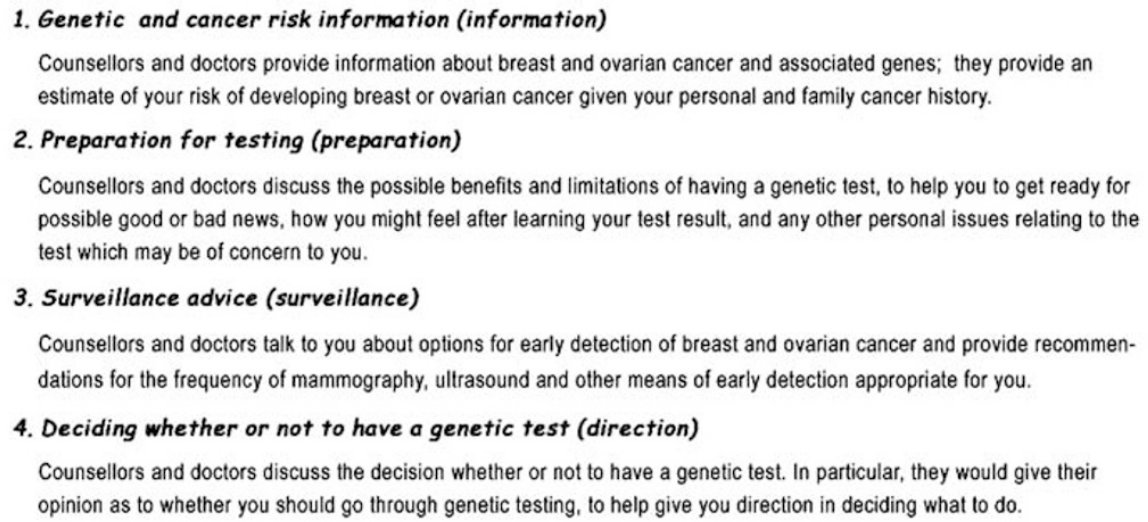

Counsellors and doctors discuss the possible benefits and limitations of having a genetic test, to help you to get ready for possible good or bad news, how you might feel after learning your test result, and any other personal issues relating to the test which may be of concern to you.

\section{Surveillance advice (surveillance)}

Counsellors and doctors talk to you about options for early detection of breast and ovarian cancer and provide recommendations for the frequency of mammography, ultrasound and other means of early detection appropriate for you.

\section{Deciding whether or not to have a genetic test (direction)}

Counsellors and doctors discuss the decision whether or not to have a genetic test. In particular, they would give their opinion as to whether you should go through genetic testing, to help give you direction in deciding what to do.

1. Please rank these four topics in order of importance to you using a scale of 1.4 , where 1 is the most important issue for discussion and 4 the least important. Please place a number in EVERY box.

\begin{tabular}{|l|}
\hline 1. Information \\
\hline 2. Preparation \\
\hline 3. Surveillance \\
\hline 4. Direction \\
\hline
\end{tabular}

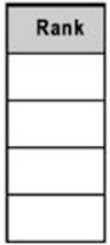

Figure I Attribute-ranking question used in the follow-up questionnaire. 


\begin{tabular}{|c|c|}
\multicolumn{1}{|c}{ Appointment A Appointment B } \\
\hline Amount of discussion & Amount of discussion \\
\hline Some & A lot \\
\hline A lot & None \\
\hline \multicolumn{2}{|c|}{ A lot } \\
\hline None & A lot \\
\hline
\end{tabular}

Which would you prefer? (tick one oniy)

Prefer A

Prefer B

Figure 2 Example of a discrete choice experiment question used in the follow-up questionnaire.

genetics services. To this end, clinical geneticists and counsellors who counselled the participants at these services played a central role in developing the descriptions. The four items and their descriptions were developed to capture information, emotional and psychosocial support, surveillance advice, and direction outcomes relevant to their practices.

Respondents were asked to rank their preferences for each of the four attributes at a genetic counselling appointment, where rank one is their most preferred and rank four is their least preferred. Strength of preference for each was then measured using a discrete choice experiment (see Figure 2).

Discrete choice experiments measure preferences by analysing individuals' responses to questions about choices they would make in hypothetical, yet realistic, situations. Respondents are asked to choose their preferred option (in this case different counselling appointments described by a unique combination of different levels for each of the counselling attributes) from a series of pairwise choices. A probabilistic discrete choice model was used to analyse the data.

Each discrete choice question asked respondents to choose between two hypothetical genetic counselling appointments described in terms of different levels of the four counselling attributes. Scenarios were paired randomly. Three attribute levels were used in the experimental design according to the amount of discussion - none, some, or a lot - devoted to each attribute during a counselling appointment. Respondents were therefore asked which of the two hypothetical genetic counselling appointments they would prefer, where alternative appointments were described in terms of different levels for the four attributes (see Figure 2). The SPEED computer package was used to select the optimal subset of scenarios, making the number of discrete choice questions manageable (Bradley, 1991).

An internal consistency test was included with the discrete choice experiment. This involved presenting a choice of counselling appointments with attribute levels such that all respondents should choose the same appointment. Only responses that showed internal consistency were included in the subset for analysis.

\section{Statistical analysis}

A random effects probit regression model was used to analyse the discrete choice data (Ryan and Farrar, 2000) using Stata v8.2.

\section{RESULTS}

\section{Respondents}

Of the 339 AJBCS participants who were sent the follow-up questionnaire (average 44 months after enrolment in the study), $256(76 \%)$ were completed and returned. Table 1 shows the mean (s.d.) age of respondents was 52.6 years (12.0). The mean number of children was 2.0 (1.2). The mean genetic knowledge score was 6.8 (1.9). The mean State Trait Anxiety Inventory score was 38.8
Table I Descriptive characteristics of respondents

\begin{tabular}{|c|c|c|}
\hline Personal characteristic & $n$ & Per cent \\
\hline \multicolumn{3}{|l|}{ Age $\mathrm{N}=210$ (years) } \\
\hline $25-54$ & 127 & $(60)$ \\
\hline $55-74$ & 74 & (35) \\
\hline $75+$ & 9 & (4) \\
\hline Mean (s.d.) & $52.56(11.96)$ & \\
\hline \multicolumn{3}{|l|}{ Number of children $\mathrm{N}=205$} \\
\hline 0 & 33 & $(16)$ \\
\hline I & 21 & (10) \\
\hline 2 or 3 & 138 & (67) \\
\hline 4 or more & 13 & $(6)$ \\
\hline Mean (s.d.) & $1.97(1.19)$ & \\
\hline \multicolumn{3}{|l|}{ University degree $\mathrm{N}=210$} \\
\hline Yes & 104 & $(50)$ \\
\hline No & 106 & $(50)$ \\
\hline \multicolumn{3}{|l|}{ Breast cancer $N=208$} \\
\hline Yes & 72 & (35) \\
\hline No & 136 & (65) \\
\hline \multicolumn{3}{|c|}{ Family history (first- and second-degree relative) N=207 } \\
\hline I case breast cancer & 74 & (36) \\
\hline 2 cases breast cancer & 51 & (25) \\
\hline 3 or more cases breast cancer & 52 & (25) \\
\hline Carrier of ancestral mutation & 30 & $(14)$ \\
\hline \multicolumn{3}{|l|}{ Genetic test result received $\mathrm{N}=210$} \\
\hline Yes & 187 & (89) \\
\hline No & 23 & (II) \\
\hline \multicolumn{3}{|l|}{ Genetic knowledge (max. 9) $N=209$} \\
\hline $1-3$ (poor) & 19 & $(9)$ \\
\hline $4-6$ (fair) & 44 & $(21)$ \\
\hline $7-9$ (good) & 146 & (70) \\
\hline Mean (Std. dev) & $6.75(1.94)$ & \\
\hline \multicolumn{3}{|l|}{ Anxiety (STAl-Trait) N=206 } \\
\hline$<40$ & 118 & $(57)$ \\
\hline $40-54$ & 67 & (33) \\
\hline $55-70$ & 21 & (10) \\
\hline Mean (s.d.) & $38.84(10.43)$ & \\
\hline \multicolumn{3}{|l|}{ Recent death of a relative $\mathrm{N}=202$} \\
\hline Yes & 44 & (22) \\
\hline No & 158 & (78) \\
\hline \multicolumn{3}{|l|}{ Recent cancer of a relative $N=202$} \\
\hline Yes & 42 & $(21)$ \\
\hline No & 160 & (79) \\
\hline
\end{tabular}

(10.4). Thirty participants were found to be mutation carriers Older women had more children $(P<0.01)$ and were more likely to have had cancer $(P<0.01)$. Younger women were more likely to 
have a university degree $(P<0.01)$, and had better genetic knowledge $(P<0.01)$. Recent death in the family was associated with a strong family history of cancer (three or more cases of breast or ovarian cancer in first- and second-degree relatives) $(P<0.01)$ and recent cancer diagnosis in the family $(P<0.01)$.

\section{Simple attribute ranking}

Simple attribute-ranking preferences are presented elsewhere (Apicella et al, 2006). More than $60 \%$ of respondents ranked information as the most important attribute. Approximately 20 and $15 \%$ of respondents ranked surveillance and preparation as the most important attribute, respectively. Only 5\% ranked direction as most important. More than $50 \%$ of respondents ranked direction as the least important attribute. Approximately $20 \%$ ranked surveillance, $25 \%$ preparation, and $5 \%$ information as least important, respectively. Preferences were not significantly different between the mutation carriers and noncarriers (Apicella et al, 2006). Rankings for the most important attribute for mutation carriers and noncarriers, respectively, were 67 and $61 \%$ for information; 13 and $20 \%$ for surveillance; 17 and $14 \%$ for preparation; 3 and 5\% for direction.

\section{Discrete choice experiment}

Of the 209 women who completed all five discrete choice questions, 193 (92\%) passed the consistency test. The random effects probit model was fitted using responses from these 193 respondents (Table 2). All main effects, the $\beta_{\mathrm{j}}$ coefficients, were positive and significant at the $1 \%$ level, except direction, which was significant at the 5\% level, showing that increased amounts of discussion for each attribute were associated with increased utility (attributes are monotonically increasing in levels).

The most important attribute was information, followed by surveillance, and then preparation (Table 2). The least important attribute was direction. The main effects, statistically significant for all four attributes, showed that increasing the level (from none to some or from some to a lot) of discussion of information, utility increased by 0.997 . Increasing the level of discussion of surveillance, preparation, and direction increased utility by $0.463,0.267$, and 0.114 , respectively.

Table 3 shows the relative value, or importance, of the different attributes, given by the ratios $\left(\beta_{\text {info }} / \beta_{\text {dirn }}\right)$ of the main effects. In

Table 2 Random effects probit model results

\begin{tabular}{lcccc}
\hline & Main effect $^{\mathbf{a}}\left(\boldsymbol{\beta}_{\mathbf{j}}\right)$ & s.e. & $\mathbf{9 5 \%} \mathbf{C l}$ & $\mathbf{P}>\mathbf{z} \mid$ \\
\hline Information & 0.997 & 0.113 & $0.776-1.218$ & 0.000 \\
Surveillance & 0.463 & 0.036 & $0.393-0.533$ & 0.000 \\
Preparation & 0.267 & 0.045 & $0.182-0.353$ & 0.000 \\
Direction & 0.114 & 0.047 & $0.023-0.206$ & 0.014 \\
\hline
\end{tabular}

$\mathrm{Cl}=$ confidence interval. Individuals $=193 ; \quad$ observations $=965 . \quad$ Log-likelihood $=-5$ 10.209; Wald $\chi^{2}(4)=250.15 ;$ Prob. $>\chi^{2}=0.000$. ${ }^{a}$ An alternative approach to estimating the main effects model is to use dummy variables for categorical attribute levels in the independent variable set. However, this approach becomes problematic owing to colinearity in the set of dummy variables.

Table 3 Relative value of attributes: ratios of main effects

\begin{tabular}{lccccc}
\hline & Main effect $\left(\boldsymbol{\beta}_{\mathbf{j}}\right)$ & $\boldsymbol{\beta}_{\mathbf{j}} / \boldsymbol{\beta}_{\text {info }}$ & $\boldsymbol{\beta}_{\mathbf{j}} / \boldsymbol{\beta}_{\text {surv }}$ & $\boldsymbol{\beta}_{\mathbf{j}} / \boldsymbol{\beta}_{\text {prep }}$ & $\boldsymbol{\beta}_{\mathbf{j}} / \boldsymbol{\beta}_{\text {dirn }}$ \\
\hline Information & 0.997 & 1.00 & 2.15 & 3.73 & 8.75 \\
Surveillance & 0.463 & 0.46 & 1.00 & 1.73 & 4.06 \\
Preparation & 0.267 & 0.27 & 0.58 & 1.00 & 2.34 \\
Direction & $0.1 \mid 4$ & 0.11 & 0.25 & 0.43 & 1.00 \\
\hline
\end{tabular}

this study, women would give up 8.75 units of discussion of direction to get an extra unit of discussion of information. That is, information was found to be almost nine times as important as direction. Alternatively, it could be viewed that women would only give up 0.11 units of discussion of information to get an extra unit of discussion of direction. These data also show that discussion of information was more than three times as important as discussion of preparation, and more than twice as important as discussion of surveillance. Similarly, discussion of surveillance was four times more important than discussion of direction, and discussion of preparation was more than twice as important as discussion of direction.

The effects of respondents' personal characteristics and experiences on the relative value of attributes were examined to determine whether preferences vary systematically between respondents. This was performed by modelling potential interactions between characteristics and preferences in the regression model (segmentation analysis). Personal characteristics included demography, education, parity, psychological well-being, personal and family cancer history, mutation carrier status, and genetic knowledge. No statistically significant relationships were identified.

\section{DISCUSSION}

Women had highest preference for information, valuing it almost nine times more than direction in decision-making about genetic testing. This is consistent with the major aims of cancer genetic services, which include providing cancer, genetic and risk information, and facilitating autonomous decision-making. Women also had high preference for discussion of breast and ovarian cancer surveillance options, valuing it twice as much as preparation for possible outcomes of genetic testing, and four times as much as direction in decision-making about genetic testing. This provides evidence that the shift towards a multidisciplinary team, which includes oncologists and surgeons able to provide surveillance advice is consistent with women's preferences for genetic counselling. The discrete choice experiment results are entirely consistent with results from attribute-ranking questions presented in Apicella et al (2006).

Although many women preferred information most, and assistance with decision-making least, there were differences between women in which aspects they most favoured. In particular, we found that some women valued preparation highly, whereas others placed least value on this aspect of genetic counselling. Since analysing these data, we have become aware of another study which has similarly found that in general, clients preferred information most and emotional support least, although a subset had high preference for emotional support (Pieterse et al, 2005b).

The results from this study suggest that a uniform and structured genetic counselling appointment may not be the best method of service delivery, as preferences vary between clients, and fulfilment of clients' preferences are important for achieving desired client outcomes. This has also been demonstrated recently by Pieterse et al (2005b), who showed that desired client outcomes such as increased perceived personal control and reduced anxiety are significantly positively associated with clients' perceptions that their preferences for service delivery were met. That is, studies that help to identify client preferences both in general and in specific subgroups may assist in improving the delivery of genetic services.

Participants of this study have undergone genetic counselling, and most have received their genetic test result, meaning that they are well placed to identify attributes of genetic services that are important to users of those services (Genetic Interest Group, 1998; Royal College of Physicians, 1998). The importance of eliciting 
preferences from respondents with first-hand experience of genetics and genetics services in understanding the attributes of genetics services has been recognised elsewhere (Wilson et al, 2000).

Given a priori expectations, the discrete choice experiment results are plausible, and provide further evidence that the technique can be successfully applied in health care. Discrete choice experiments have been shown to provide internally valid and consistent responses (Viney et al, 2002; Ryan and Gerard, 2003; Ryan et al, 2003). However, this may depend on study context (Ryan and Gerard, 2002), and there is some evidence that some respondents may not trade-off attributes, but adopt simpler decision heuristics (Scott, 2002; Lloyd, 2003). Although the choices presented to respondents are hypothetical, this allows researchers to have complete control over experimental design and ensures statistical robustness (Ubach et al, 2003). An important question with any stated preference technique is that of external validity: would respondents make the same choices in reality? Surveying respondents with first-hand experience genetics services, and evidence from other areas such as the valuation of environmental goods and services means that we can be optimistic (Wilson et al, 2000; Ryan, 2004). Clearly, future research on these topics is warranted.

It remains to be seen whether results from this study are generalisable to other populations and to other types of genetic testing, owing to differences in the characteristics of participants of this study and of other populations seeking cancer genetic counselling. Such differences include; specific testing with a more definitive outcome was conducted in the Ashkenazi Jewish population, whereas there is often no definitive outcome from BRCA1 and BRCA2 testing in the general population; the extent of family cancer history of participants may differ from other populations undergoing BRCA1 and BRCA2 testing; and, other cultural groups may value counselling outcomes differently. Nonetheless, a study of preferences for cancer genetic counselling in a Dutch population found that clients had similar preferences to

\section{REFERENCES}

Apicella C, Andrews L, Hodgson SV, Fisher SA, Lewis CM, Solomon E, Tucker K, Friedlander M, Bankier A, Southey MC, Venter DJ, Hopper JL (2003) Log odds of carrying an Ancestral Mutation in BRCA1 or BRCA2 for a defined personal and family history in an Ashkenazi Jewish woman (LAMBDA). Breast Cancer Res 5: R206-R216, doi:10. $1186 /$ bcr644

Apicella C, Peacock S, Andrews L, Tucker K, Bankier A, Daly MB, Hopper JL (2006) Determinants of preferences for genetic counselling in Jewish Women. Fam Cancer 5: 159-167, doi:10.1007/s10689-005-3871-7

Berkenstadt M, Shiloh S, Barkai G, Katznelson MB, Goldman B (1999) Perceived personal control (PPC): a new concept in measuring outcome of genetic counseling. Am J Med Genet 82: 53-59, doi:10.1002/ (SICI)1096-8628(19990101)82:1

Bernhardt BA, Biesecker BB, Mastromarino CL (2000) Goals, benefits, and outcomes of genetic counseling: client and genetic counselor assessment. Am J Med Genet 94: 189-197

Bradley M (1991) User's Manual for SPEED Version 2.1 Stated Preference Experiment Editor and Designer. Hague: Hague Consulting Group

Brain K, Gray J, Norman P, France E, Anglim C, Barton G, Parsons E, Clarke A, Sweetland H, Tischkowitz M, Myring J, Stansfield K, Webster D, Gower-Thomas K, Daoud R, Gateley C, Monypenny I, Singhal H, Branston L, Sampson J, Roberts E, Newcombe R, Cohen D, Rogers C, Mansel R, Harper P (2000) Randomized trial of a specialist genetic assessment service for familial breast cancer. J Natl Cancer Inst 92: $1345-1351$

Cappelli M, Surh L, Humphreys L, Verma S, Logan D, Hunter A, Allanson J (2001) Measuring women's preferences for breast cancer treatments and BRCA1/BRCA2 testing. Qual Life Res 10: 595-607, doi:10.1023/ A:1013123915272

Clarke A, Parsons E, Williams A (1996) Outcomes and process in genetic counselling. Clin Genet 50: $462-469$ those identified in this study of Australian Jewish women (Pieterse et al, 2005b), suggesting that findings from this study may apply to other populations.

The discrete choice experiment technique could be further used to elicit client preferences for a range of other health and nonhealth objectives relating to genetics services. In particular, access to genetics services may be improved if genetics testing becomes available through general practitioners on a widespread basis. However, this might be associated with a more limited service for clients, as most general practitioners will not have the time or level of genetics training as found in dedicated genetic clinics. A discrete choice experiment could be used to measure the value that clients place on improving access to genetics services relative to the amount of information and other aspects of genetic counselling that they would receive from their local family doctor compared to a genetic clinic.

\section{ACKNOWLEDGEMENTS}

This study was funded by the National Cancer Institute (USA) as part of the Breast Cancer Family Registry, and supported in Australia by the Australian National Health and Medical Research Council. Stuart Peacock is a Michael Smith Foundation for Health Research Scholar. We wish to express our appreciation to the women and their relatives who participated in this study. The views expressed in this paper are those of the authors, not the funding agencies.

Ethics approval: The study was approved by the Human Research Ethics Committees of the Peter MacCallum Cancer Institute (Melbourne), The Prince of Wales Hospital (Sydney), and The University of Melbourne. Written informed consent was obtained from all participants in accordance with each ethics committee's requirements.
Cohn WF, Ropka ME, Jones SM, Miesfeldt S (2003) Information needs about hereditary breast cancer among women with early-onset breast cancer. Can Detect Prev 27: 345 -352, doi:10.1016/j.cdp.2003.07.001

Fodor FH, Weston A, Bleiweiss IJ, McCurdy LD, Walsh MM, Tartter PI, Brower ST, Eng CM (1998) Frequency and carrier risk associated with common BRCA1 and BRCA2 mutations in Ashkenazi Jewish breast cancer patients. Am J Hum Genet 63: 45-51

Genetic Interest Group (1998) Guidelines for Genetics Services. A Working Party Report. London: GIG

Hallowell N, Murton F, Statham H, Green JM, Richards MP (1997) Women's need for information before attending genetic counselling for familial breast or ovarian cancer: a questionnaire, interview, and observational study. BMJ 314: $281-283$

Hartge P, Struewing JP, Wacholder S, Brody LC, Tucker MA (1999) The prevalence of common BRCA1 and BRCA2 mutations among Ashkenazi Jews. Am J Hum Genet 64: $963-970$

Holloway S, Porteous M, Cetnarskyj R, Anderson E, Rush R, Fry A, Gorman D, Steel M, Campbell H (2004) Patient satisfaction with two different models of cancer genetic services in south-east Scotland. Br J Cancer 90: 582 - 589, doi:10:1038/sjbjc6601562

John EM, Hopper JL, Beck JC, Knight JA, Neuhausen SL, Senie RT, Ziogas A, Andrulis IL, Anton-Culver H, Boyd N, Buys SS, Daly MB, O’Malley FP, Santella RM, Southey MC, Venne VL, Venter DJ, West DW, Whittemore AS, Seminara D, Breast Cancer Family Registry (2004) Breast Cancer Family Registry: an infrastructure for cooperative multinational, interdisciplinary and translational studies of the genetic epidemiology of breast cancer. Breast Cancer Res 6: R375-R389, Epub 2004 May 19, doi:10.1196/bcr901

Lloyd AJ (2003) Threats to the estimation of benefit: are preference elicitation methods accurate? Health Econ 12: 393-402, doi:10.1002/ nec.772 
Metcalfe KA, Liede A, Hoodfar E, Scott A, Foulkes WD, Narod SA (2000) An evaluation of needs of female BRCA1 and BRCA2 carriers undergoing genetic counselling. J Med Genet 37: 866-874

Pieterse A, van Dulmen S, Ausems M, Schoemaker A, Beemer F, Bensing J (2005a) QUOTE-gene(ca): development of a counselee-centered instrument to measure needs and preferences in genetic counseling for hereditary cancer. Psycho-oncology 14: $361-375$

Pieterse AH, Ausems MG, Van Dulmen AM, Beemer FA, Bensing JM (2005b) Initial cancer genetic counseling consultation: change in counselees' cognitions and anxiety, and association with addressing their needs and preferences. Am J Med Genet 137A: 27-35

Robson M, Dabney MK, Rosenthal G, Ludwig S, Seltzer MH, Gilewski T, Haas B, Osborne M, Norton L, Gilbert F, Offit K (1997) Prevalence of recurring BRCA mutations among Ashkenazi Jewish women with breast cancer. Genet Test 1: 47-51

Royal College of Physicians (1998) Commissioning Clinical Genetics Services. London: Royal College of Physicians

Ryan M (1999) Using conjoint analysis to go beyond health outcomes: an application to in vitro fertilisation. Soc Sci Med 48: 535 - 546, doi:10.1016/ SO277-9536(98)00374-8

Ryan M (2004) Discrete choice experiments in health care. BMJ 328: 360 - 361, doi:10.11361/bmj.328.7436.360

Ryan M, Farrar S (2000) Using conjoint analysis to elicit preferences for health care. BMJ 320: 1530-1533, doi:10.1136/bmj.320.7248. 1530

Ryan M, Gerard K (2002) Using discrete choice experiments in health economics: moving forward. In Advances in Health Economics Scott A, Maynard A, Elliott R (eds) pp 25-40. Chichester: Wiley

Ryan M, Gerard K (2003) Using discrete choice experiments to value health care: current practice and future prospects. Appl Health Econ Policy Analysis 2: 55-64

Ryan M, Watson V, Amaya-Amaya M (2003) Methodological issues in the monetary valuation of benefits in health care. Exp Rev Pharmacoecon Outcomes Res 3: 717-727

Satagopan JM, Offit K, Foulkes W, Robson ME, Wacholder S, Eng CM, Karp SE, Begg CB (2001) The lifetime risks of breast cancer in Ashkenazi
Jewish carriers of BRCA1 and BRCA2 mutations. Cancer Epidemiol Biomark Prevent 10: $467-473$

Scott A (2002) Identifying and analysing dominant preferences in discrete choice experiments: an application in health care. J Econ Psyc 23: 383 398, doi:10.1016/SO167-4870(02)00082-X

Sculpher M, Bryan S, Fry P, de Winter P, Payne H, Emberton M (2004) Patients' preferences for the management of non-metastatic prostate cancer: discrete choice experiment. BMJ 328: 382-385, doi:10.1136/ bmj.37972.497234.44

Shiloh S, Avdor O, Goodman RM (1990) Satisfaction with genetic counseling: dimensions and measurement. Am J Med Genet 37: 522-529

Stadler MP, Mulvihill JJ (1998) Cancer risk assessment and genetic counseling in an academic medical center: consultands' satisfaction, knowledge, and behaviour in the first year. J Genet Couns 7: 279-297

Struewing JP, Hartge P, Wacholder S, Baker SM, Berlin M, McAdams M, Timmerman MM, Brody LC, Tucker MA (1997) The risk of cancer associated with specific mutations of BRCA1 and BRCA2 among Ashkenazi Jews. $N$ Engl J Med 336: $1401-1408$

Thompson JA, Wiesner GL, Sellers TA, Vachon C, Ahrens M, Potter JD, Sumpmann M, Kersey J (1995) Genetic services for familial cancer patients: a survey of National Cancer Institute cancer centers. J Natl Cancer Inst 87: 1446-1455

Tiller K, Meiser B, Gould L, Tucker K, Dudding T, Franklin J, Friedlander M, Andrews L (2005) Knowledge of risk management strategies, and information and risk management preferences of women at increased risk for ovarian cancer. Psycho-Oncol 14: 249-261, doi: 10.1002/pon.840

Ubach C, Scott A, French F, Awramenko M, Needham G (2003) What do hospital consultants value about their jobs? A discrete choice experiment. BMJ 326: 1432 - 1442, doi:10.1136/bmj.326.7404.1432

Viney R, Lancsar E, Louviere J (2002) Discrete choice experiments to measure preferences for health and health care. Exp Rev Pharmacoecon Outcomes Res 2: 319-326

Wilson B, Ryan M, Haites N (2000) Assessing User Preferences for, and Costs of, Genetic Counselling for Familial Cancer Risk in Scotland: A CostUtility Analysis Using Conjoint Analysis. Scottish: Report to the Chief Scientist Office, Executive Health Department 